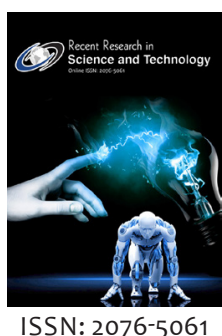

*Corresponding Author: Rahat Pervez

E-mail: rahat335@gmail.com

\section{Augmented reality marker-based technology for augmenting newspaper advertisement}

\section{Rahat Pervez ${ }^{1 *}$, Diba Chowdhury', Md. Sahadat Hossain Sagor ${ }^{2}$, Md. Imdadul Hoque ${ }^{3}$, Nafiul Islam}

\begin{abstract}
'Department of Electrical and Computer Engineering, North South University, Dhaka - 1229, Bangladesh, 2Department of Information Technologies, Czech University of Life Science, Kamýcká 129, 16521 Prague, Czech Republic, ${ }^{3}$ Department of Communication and Information Technology, University of Bremen, 28359 Bremen, Germany
\end{abstract}

Recent Research in Science and Technology, 2021, 13, 13-18. https://doi.org/10.25081/rrst.2021.13.7005

One of the authors' (Md. Imdadul Hoque ${ }^{3}$ ) affiliations was mentioned incorrectly. It should be read as follows:

${ }^{3}$ Department of Computer Science and Telecommunication Engineering, Noakhali Science and Technology University, Noakhali - 3814, Bangladesh 